\title{
Editorial of the Special Issue of MCAP: In Honour of Claude Lefèvre on Risk, Epidemics, Stochastic Orderings, Health and Economics
}

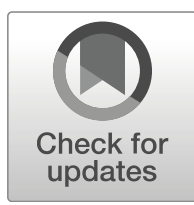

\section{Richard Kryscio ${ }^{1}$. Stéphane Loisel ${ }^{2} \cdot$ André de Palma $^{3}$. Pierre Patie ${ }^{4}$}

Received: 25 February 2019/

Accepted: 26 February 2019 / Published online: 22 March 2019

(C) Springer Science+Business Media, LLC, part of Springer Nature 2019

This Special Issue of Methodology and Computing in Applied Probability (MCAP) is in honour of Professor Claude Lefèvre, who is currently emeritus professor at Université Libre de Bruxelles and researcher at the Laboratoire de Science Actuarielle et Financière, ISFA, Université Lyon 1. Claude has been serving as associate editor of MCAP for many years, and a research day in his honour was organized at Institut de Science Financière et d'Assurances (Université Lyon 1) in September 2016 as a satellite event of the $3^{\text {rd }}$ European Actuarial Journal Conference. The present special issue was guest edited by the organizers of the event. It contains fourteen papers. Some of these articles were presented during the conference. The variety of fields covered by the papers of this special issue illustrate the breadth of Claude's research spectrum.

Claude Lefèvre's research career was based at the Université Libre de Bruxelles (ULB). He obtained a Bachelor Degree in Actuarial Science and defended a PhD thesis in Mathematics

Richard Kryscio

kryscio@email.uky.edu

Stéphane Loisel

loisel@univ-lyon1.fr

André de Palma

andre.depalma@ens-cachan.fr

Pierre Patie

pp396@cornell.edu

1 Sanders-Brown Center On Aging, University of Kentucky, 800 South Limestone Street, Lexington, KY 40536-0230, USA

2 ISFA, LSAF EA2429, University of Lyon, Université Lyon 1, 50, avenue Tony-Garnier, F-69007 Lyon, France

3 Département Economie et Gestion, Ecole Normale Supérieure de Cachan, 61, avenue du Président Wilson, 94230 Cachan, France

4 School of Operations Research and Information Engineering, Cornell University, 219 Rhodes Hall Ithaca, Ithaca, NY 14853, USA 
(probability theory) under the supervision of Jean Teghem. He held the position of professor at ULB during his entire career, but visited regularly several universities, including in particular University of Kentucky, University of California at Santa Barbara and Joe Gani, Université de Montpellier, ISFA, University of Roma, University of Barcelona, Université Internationale de Rabat, Université Saint Joseph (Beyrouth) and National Economics University (Hanoï).

Claude's research portfolio ranges from theoretical probability to applied probability with a focus on actuarial science and epidemiology. In probability theory, he worked on first passage problems, Stein method and Poisson approximations. In applied probability, he used tools like polynomials, martingales, as well as stochastic orderings and measures to address insurance and bio-mathematics research problems. Focusing on insurance applications, Claude published numerous papers on risk theory, ruin problems, risk measures and stochastic dependence between risks. His favourite research output corresponds to his findings on the underlying polynomial algebraic structure in ruin and epidemics models.

Claude collaborated with researchers from several different fields. The breadth of his research spectrum was reflected in the set of invited speakers of the research day who collaborated with him. Claude published many inspiring papers with one of his first $\mathrm{PhD}$ students Michel Denuit, in particular about stochastic orders and actuarial sciences. He also worked and regularly exchanged ideas with Frank Ball on epidemics processes, with Marie-Pierre Malice on comparison of epidemics, with Sergey Utev on probability theory and insurance, with Dimitrios Konstantinides on risk theory, with Mercè Claramunt on stochastic dependence between risks, ruin and reinsurance, and with André de Palma on discrete choice models and dynamic models in transportation science.

The research day in honour of Claude was organized in Lyon since Claude Lefèvre has a long-lasting collaboration with ISFA, as invited professor and lecturer, and as regular coauthor of Philippe Picard (former Head of ISFA) and Stéphane Loisel. Claude co-authored papers with many researchers, including Romain Biard, Christophe Dutang, Pierre-Olivier Goffard, Manel Kacem, Matthieu Simon, Julien Trufin, Anna Castañer, Moshe Ben-Akiva, Richard Kryscio, M'hamed Mesfioui, Haikady Nagaraja, Vassilis Papathanasiou, Marco Scarsini and Moshe Shaked. The full list of Claude's co-authors is available on his webpage.

Claude has served for many years as associate editor of MCAP, in collaboration with the editor-in-chief Joe Glaz, and as associate editor of Communications in Statistics with the editor-in-chief Narayanaswamy Balakrishnan.

Claude mentored young researchers by writing many papers with his doctoral students and students of his co-authors. He was the PhD advisor of Abdelghani Kissami (1993), Michel Denuit (1997), M'hamed Mesfioui (1998), Rachid Massaad (2004), Maude Gathy (2010) and Rabih Badran (2014, with J.-M. Reinhard).

In addition to his service on the editorial boards of MCAP and Communications in Statistics, Claude has been a member of the organizing committee of several important actuarial conferences including Confererence in Actuarial Science and Finance on Samos (CASF Samos), Stochastic Modeling Techniques and Data Analysis International Conference (SMTDA), Applied Stochastic Models and Data Analysis International Conference 
(ASMDA), and International Workshop on Applied Probability (IWAP).

Claude has always been an enthusiastic academic, driven by research and the need to understand complex problems. He has a high standard, and the quality of his ideas and of his writing remain unquestionable. He is a colleague that many of us would like to have, and his sense of humour is a real plus in the academic world.

Acknowledgments The guest editors of this Special Issue of MCAP would like to thank Pierre Montesinos for interviewing Claude in the preparation of this editorial.

Publisher's Note Springer Nature remains neutral with regard to jurisdictional claims in published maps and institutional affiliations. 